\title{
Ion-pair Spectrophotometric Determination of Dibucaine
}

\author{
Raqi M. Shubietah*a ${ }^{*}$ Ali Z.Abu Zuhri ${ }^{\mathrm{b}}$ and Bashar A. Khalid \\ a: Faculty of Pharmacy, b: Department of Postgraduate Studies; \\ An-Najah National University, P.O.Box 7, Nablus, Palestine, via Israel
}

Abstract: A simple and sensitive spectrophotometric determination of dibucain has been established. It is based on the formation of colored ion-pair complexes between Dibucaine and each of Orange II, Orange G, Bromothymol blue and Bromocresol green. The extract with each of the previous dyes in chloroform exhibited a specific wavelength of maximum absorbance, and all these wavelengths lied in the range 416 to $500 \mathrm{~nm}$. The linear range extended from 1.5 to $60 \mathrm{ppm}$. The optimum conditions were selected after studying many variables such as $\mathrm{pH}$, shaking time, temperature and dye concentrations. The method was also selective for the analyte and the drug excipients did not interfere.

Keywords : Dibucaine, Ion-pair spectrometry

\section{Introduction}

Dibucaine [[2-butoxy-N-(2-diethylamino)ethyl]-4-quinolinecarboxamide monohydrochloride] is a local anesthetic drug and was first synthesized by Miescher ${ }^{(1)}$ in 1932. Dibucaine (cinchocaine), $\mathrm{C}_{20} \mathrm{H}_{29} \mathrm{~N}_{3} \mathrm{O}_{2} . \mathrm{HCl}$, was one of the famous families, which can be classified as local anesthetic, such as Procaine, Cocaine, Lignocaine and Prilocaine ${ }^{(2,3)}$.

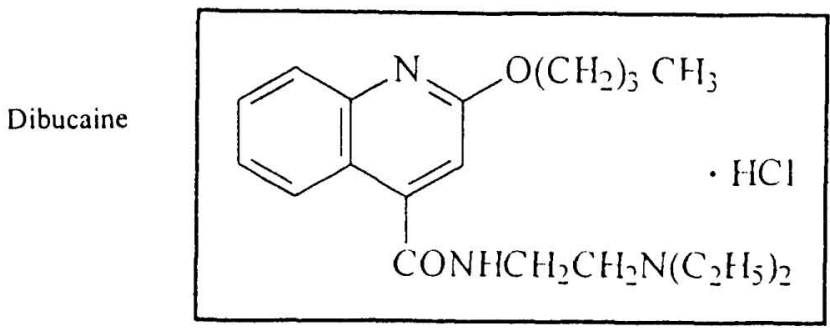


This drug is about 15 times more potent than procaine and 5 times more potent than cocaine in producing local anesthesia, but it is also considerably more poisonous ${ }^{(4)}$. It is used for temporary relief of painful sunburn, minor burns, scrapes, scratches, nonpoisonous insect bites, external hemorrhoidal pain, and as an injectable preparation for spinal anesthesia ${ }^{(5,6)}$. Dibucaine is readily absorbed through the mucous membranes and should not be used around the eyes or mouth. David et al ${ }^{(5)}$ reported a new method for the determination of dibucaine in biological fluids using gas chromatography/mass spectrometer. The detection limit was in the range of 1-80 $\mathrm{ng} / \mathrm{mL}$ of serum.

Igrashi, et al ${ }^{(7)}$ reported a method for determination of Dibucaine and its metabolites in human urine by high performance liquid chromatography with fluorescence detector. Other workers ${ }^{(8)}$ reported an HPLC method also for the drug determination in serum. A single method has been reported in the literature for the electrochemical determination of Dibucaine by its reduction on a mercury electrode $\left(10^{-6} \text { to } 10^{-4} \mathrm{M}\right)^{(9)}$.

Mohamed et al ${ }^{(10)}$ reported a spectrophotometric method for the determination of Dibucaine and eight related drugs. Beer's law was obeyed for $5-30 \mu \mathrm{g} / \mathrm{mL}$ Dibucaine and the detection limit was in the range $1-3.7 \mu \mathrm{g} / \mathrm{ml}$. The aim of our work here is to develop a new spectrophotometric method for the determination of Dibucaine in pharmaceutical formulations. It was based on the formation of ion-pairs 
between Dibucaine and the positively charged dyes (e.g. BTB, BCG, OrgG and Org II); the produced colored ion-pair can be extracted to an organic phase and determined spectrophotometrically. The sensitivity and selectivity of the suggested method was compared with other previously reported methods.

\section{Experimental}

Absorbance measurements were carried out using a UV-2 UNICAM UV-VIS spectrophotometer with $1-\mathrm{cm}$ quartz cells. The $\mathrm{pH}$ measurements were carried out using a (HANNA, model HI 8424) pH- meter. The temperature was controlled using Techne, circulator v-85 A. Dibucaine, Procaine, Prilocaine, Prilocainamide, Orange II, and Orange G were obtained from SIGMA company. Bromothymol blue (BTB) and bromocresol green $(\mathrm{BCG})$ were obtained from $\mathrm{BDH}$. All materials were used without further purification.

\section{Dibucaine stock solution $\left(1.0 \times 10^{-3} \mathrm{M}\right)$}

A $1.0 \times 10^{-3} \mathrm{M}$ standard aqueous solution of Dibucaine was freshly prepared by dissolving an appropriate amount of pure drug (exactly $0.0379 \mathrm{~g}$ Dibucaine) in $100 \mathrm{ml}$ of doubly distilled water in $100-\mathrm{ml}$ volumetric flask. All solutions were prepared weekly and stored in the refrigerator.

\section{Orange II and orange G solutions $\left(1.0 \times 10^{-3} \mathrm{M}\right)$}

Dye solutions were prepared by dissolving exactly $0.03503 \mathrm{~g}$ and $0.04524 \mathrm{~g}$ of 
orange II and orange $\mathrm{G}$, respectively in a $100-\mathrm{ml}$ doubly distilled water. The stock solutions were freshly prepared every two weeks.

A $1.0 \times 10^{-3} \mathrm{M}$ of each BTB and BCG solutions were prepared by dissolving exactly $0.0624 \mathrm{~g}$ and $0.0698 \mathrm{~g}$ of BTB and BCG, respectively in $2 \mathrm{ml}$ of $0.1 \mathrm{M}$ sodium hydroxide, followed by the addition of $20 \mathrm{ml}$ ethanol (96\%) then the volume was completed to $100 \mathrm{ml}$ using doubly distilled water.

\section{Recommended procedure}

A measured amount of dye $\left(4.0 \times 10^{-5} \mathrm{M}\right.$ in the case of orange II, BTB and $\mathrm{BCG}$, and $8.0 \times 10^{-5} \mathrm{M}$ in the case of orange $\mathrm{G}$ ) was transferred into a $100-\mathrm{ml}$ separatory funnel, then $5 \mathrm{ml}$ of BR-buffer solution of the desired $\mathrm{pH}$ were added. An accurate amount of solution containing Dibucaine in the range $1.5-60 \mu \mathrm{g} / \mathrm{ml}$ was added and followed by $20 \mathrm{ml}$ of organic solvent. The mixture was shaken vigorously for $30-60 \mathrm{~s}$ and allowed separating into two phases. The organic phase was collected in a $25-\mathrm{ml}$ volumetric flask and the volume was completed to the mark with the organic solvent.

Blank solution was prepared at the same time under the same conditions. The absorbance of the formed complex was measured at 486, 500, 418 and $416 \mathrm{~nm}$ wavelengths for orange II, orange $\mathrm{G}, \mathrm{B}$ TB and $\mathrm{BCG}$, respectively. The amount of Dibucainc was determined from the already constructed calibration curves. 


\section{Results and discussion}

\section{Effect of $\mathrm{pH}$ and solvents}

The effect of $\mathrm{pH}$ of the aqueous phase on the extraction efficiency of Dibucaine ion-pairs were studied in the $\mathrm{pH}$ range 1.7-10.0 for solutions prepared as described in the general procedure. The results obtained indicated that the absorbance of the organic phase for all the systems was maximum within the $\mathrm{pH}$ range $1.7-4.0$. A further increase in the $\mathrm{pH}$ affected a remarkable decrease in the absorbance. Dibucaine ion-pair complexes with OrgIl, OrgG, BTB and BCG showed absorption maxima at 486, 500, 418 and $418 \mathrm{~nm}$, respectively. In the present work, $\mathrm{pH} 1.75$ was selected as optimum for further work when using OrgII and OrgG, and pH 3.00 when using BTB and BCG.

In the proposed methods, chloroform was found to be the most suitable for extraction of Dibucaine-OrgII and Dibucaine-OrgG ion-pairs, while dichloromethane was found to be the most suitable for extraction of Dibucaine-BTB and DibucaineBCG ion-pairs. A single extraction for $60 \mathrm{~s}$ with $20 \mathrm{ml}$ organic solvent was found to have excellent extraction efficiency. BR buffer gave maximum absorbance and was chosen as optimum. The stability of the ion-pair complexes in the organic layer was determined by measuring the absorbance over a period of time. The colour of the 
Dibucaine-dye ion-pair developed instantly and the intensity remained almost constant for at least 120 hours.

\section{Table (1)}

Effect of type of organic solvent on the percent of extraction of Dibucaine in presence of OrgII, OrgG, BTB, and BCG dyes at the optimum conditions.

\begin{tabular}{|c|c|c|c|c|c|c|c|c|}
\hline Organic & Orange II & & Orange $\mathrm{G}$ & & BTB & & BCG & \\
\hline & $\bar{A}$ & $\% \mathrm{E}$ & $\mathrm{A}$ & $\% \mathrm{E}$ & A & $\% \mathrm{E}$ & $\mathrm{A}$ & $\% \mathrm{E}$ \\
\hline Chloroform & $\underline{0.811}$ & $\underline{100}$ & $\underline{0.422}$ & $\underline{100}$ & 0.724 & 94.4 & 0.709 & 91.9 \\
\hline Dichloromethane & 0.789 & 97.3 & 0.314 & 74.4 & $\underline{0.767}$ & $\underline{100}$ & $\underline{0.771}$ & $\underline{100}$ \\
\hline Toluene & 0.404 & 49.9 & 0.052 & 5.9 & 0.508 & 66 & 0.598 & 77.6 \\
\hline Diethylether & 0.046 & 7.9 & 0.008 & 1.9 & 0.528 & 68.8 & 0.599 & 77.7 \\
\hline Carbon tetrachloride & 0.012 & 1.5 & 0.104 & 24.6 & 0.743 & 96.8 & 0.592 & 76.7 \\
\hline$n$-hexane & 0.010 & 1.2 & 0.009 & 2.1 & 0.580 & 75.6 & 0.001 & 0.13 \\
\hline
\end{tabular}

$[$ Dibucaine $]=[\mathrm{Org} I \mathrm{I}]=[\mathrm{BTB}]=[\mathrm{BCG}]=4.0 \times 10^{-5} \mathrm{M},[\mathrm{OrgG}]=8.0 \times 10^{-5} \mathrm{M}$.

Temp. $=25^{\circ} \mathrm{C}, \mathrm{pH}=1.75$ for Orgll, OrgG and 3.00 for BTB, BCG.

\section{$\underline{\text { Interference }}$}

The effect of various pharmaceutical excipients and similar compounds fron the family of Dibucaine on the determination of $4.0 \times 10^{-5} \mathrm{M}$ of dibucaine was investigated. These included Procaine, Procainamide, Prilocaine, and other excipients 
e.g. starch, talc powder, lactose, glucose, and magnesium stearate in the range of $4.0 \times$ $10^{-7}-4.0 \times 10^{-5} \mathrm{M}$.

It was found that the presence of excipients did not exhibit any significant interference in the determination of Dibucaine. On the other hand, in presence of OrgG dye, $4.0 \times 10^{-5} \mathrm{M}$ of each Procainamide and Prilocaine. A significant interference has been observed in the presence of small amounts of Procaine, Procainamide, and Prilocaine $\left(4.0 \times 10^{-5} \mathrm{M}\right)$ in case of BTB dye.

\section{Beer's law and sensitivity}

The calibration graphs were plotted under the optimum conditions recommended in the general procedure. The graphs obey Beer's law (Linear relationship between the absorbance and the Dibucaine concentration) over the concentration range $0.8-15 \mathrm{ppm}, 3.7-61 \mathrm{ppm}, 1.5-17 \mathrm{ppm}$ and $1.5-18 \mathrm{ppm}$ for Orange II, Orange G, BTB, and BCG systems, respectively. Fig 1 shows this data for orange II dye complex with Dibucaine. The Molar absorptivities $(\varepsilon)$ were calculated from the linear part of the curve and found to be $2.0 \times 10^{4} \mathrm{~L} \mathrm{~mol}^{-1} \mathrm{~cm}^{-1}, 5.7 \times 10^{3} \mathrm{~L} \mathrm{~mol}^{-1}$ $\mathrm{cm}^{-1}, \quad 1.6 \times 10^{4} \mathrm{~L} \mathrm{~mol}^{-1} \mathrm{~cm}^{-1}$, and $2.2 \times 10^{4} \mathrm{~L} \mathrm{~mol}^{-1} \mathrm{~cm}^{-1}$ for Orange II, Orange G, BTB, and BCG systems, respectively. The relative standard deviations (RSD) were calculated for each of the above ion-pair complexes, and found to be $0.71 \%$ and $0.65 \%$ for Orange II and Orange G, respectively, and $0.55 \%$ for BTB and BCG. These values indicated the good reproducibility of the proposed methods. 
The composition of the ion-pair complexes between Dibucaine and the investigated dyes were determined using the molar ratio method ${ }^{(11)}$. In this method, a series of solutions containing different concentrations of the dye were prepared. The concentration of Dibucaine and all other conditions were kept constant. The absorbance of the formed complexes were measured at $\lambda_{\max }$ for each complex and plotted versus the mole ratio dye/Dibucaine. Figure 2 indicates that the ion-pair complexes have a 1:1 stoichiometric ratio.

\section{Table (2)}

Analytical characteristics for the ion-pair formation methods

\begin{tabular}{lcccc}
\hline Parameter & Org II method & Org G method & BTB method & BCG method \\
\hline$\lambda_{\max }(\mathrm{nm})$ & 486 & 500 & 418 & 416 \\
Amount of buffer $(\mathrm{ml})$ & 5 & 5 & 5 & 5 \\
Recommended optimum pH & 1.75 & 1.75 & 3.00 & 3.00 \\
Shaking time $(\mathrm{s})$ & 60 & 30 & 30 & 60 \\
Concentration of dye $(\mathrm{M})$ & $4.0 \times 10^{-5}$ & $8.0 \times 10^{-5}$ & $4.0 \times 10^{-5}$ & $4.0 \times 10^{-5}$ \\
Molar absorbtivity $\left(\mathrm{L} \mathrm{mol}^{-1} \mathrm{~cm}^{-1}\right)$ & $2.0 \times 10^{4}$ & $5.68 \times 10^{3}$ & $1.6 \times 10^{4}$ & $2.2 \times 10^{4}$ \\
Detection limits $\left(\mu \mathrm{g} \mathrm{ml}^{-1}\right)$ & 0.8 & 3.8 & 1.5 & 1.5 \\
Range of linearity $\left(\left.\mu \mathrm{g} \mathrm{ml}\right|^{-1}\right)$ & $0.8-19.0$ & $3.8-60.8$ & $1.5-16.7$ & $1.5-18.2$ \\
RSD $(\mathrm{n}=5)$ & $0.72 \%$ & $0.66 \%$ & $0.55 \%$ & $0.55 \%$ \\
\hline
\end{tabular}




\section{Comparison of the proposed method with other published methods}

Very few spectrophotometric and chromatographic methods and only a single electrochemical method have been reported for the determination of Dibucaine in pharmaceutical formulations. It was found that the suggested method is highly sensitive and competes well with other methods. Table 3 shows comparison between the proposed method and other reported methods.

\section{Determination of Dibucaine in Sheriproct Ointment}

An ointment called Sheriproct, manufactured in Madrid-Spain, was obtained and analyzed as mentioned in the recommended procedure. OrgII dye was used at $\mathrm{pH} 1.75$. After extraction with $25 \mathrm{ml}$ of chloroform, a solution of this ointment containing $30 \mu$ $\mathrm{g}$ Dibucaine/ml. The absorbance was then measured at $486 \mathrm{~nm}$ versus a similar preparation without ointment (blank). From the calibration graph, it was observed that the assay has a minimum of $93 \%$ and a maximum of $96 \%$ of the labeled amount. The RSD for six different measurements at the same level was about $1.5 \%$.

Conclusion The use of the proposed method for quantitative determination of Dibucaine allows a selective and quantitative analysis. The results also showed that there is no significant interference from many of the excipients and similar drugs from the same family. The method is applicable to the analysis of trace amounts of Dibucaine in pharmaceutical formulations with a satisfactory reproducibility. 
R. M. Shubiet ah et al.:

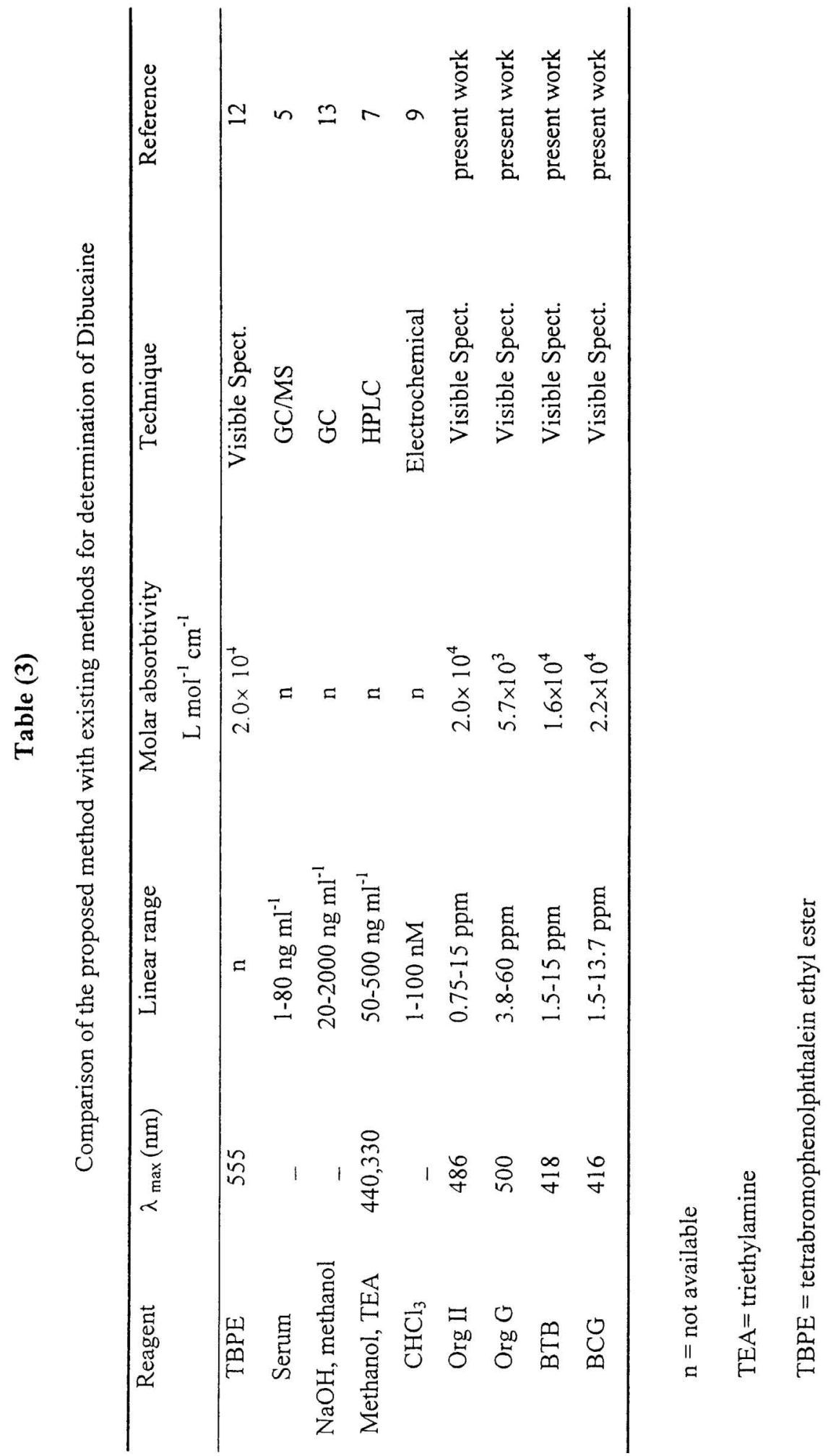




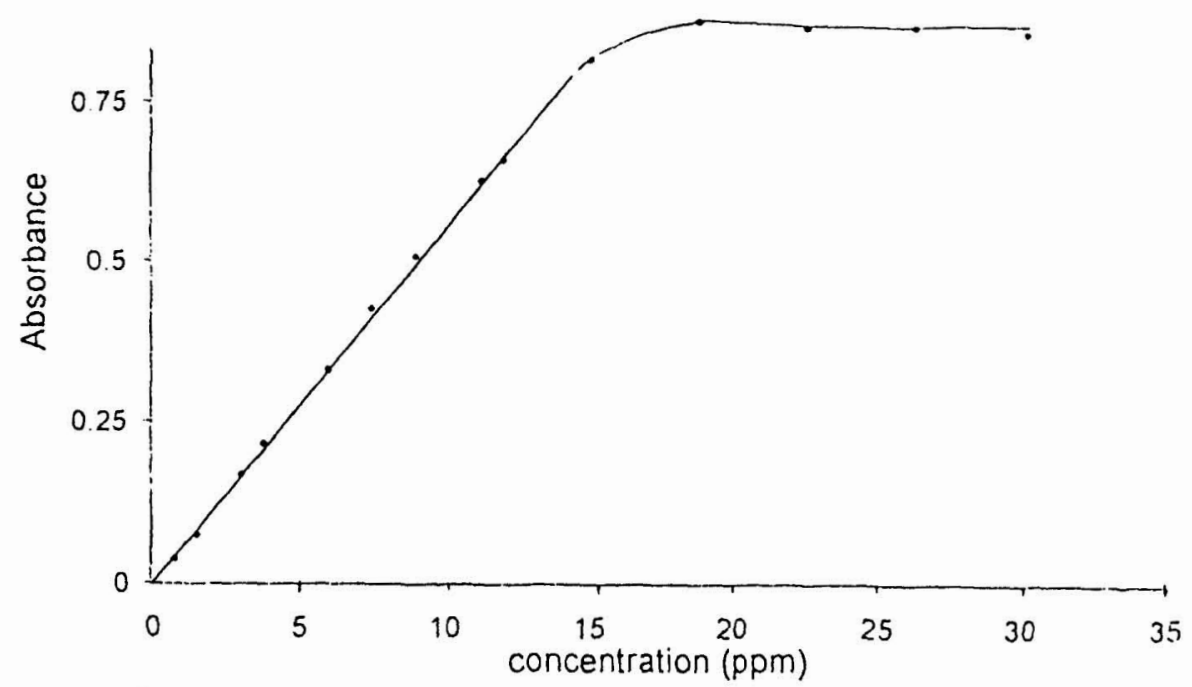

Figure 1

Calibration graph for the determination of Dibucaine using OrgII, with conccentration of $\operatorname{OrgII}=4.0 \times 10^{-5} \mathrm{M}, \mathrm{pH}=1.75$ at $486 \mathrm{~nm}$.

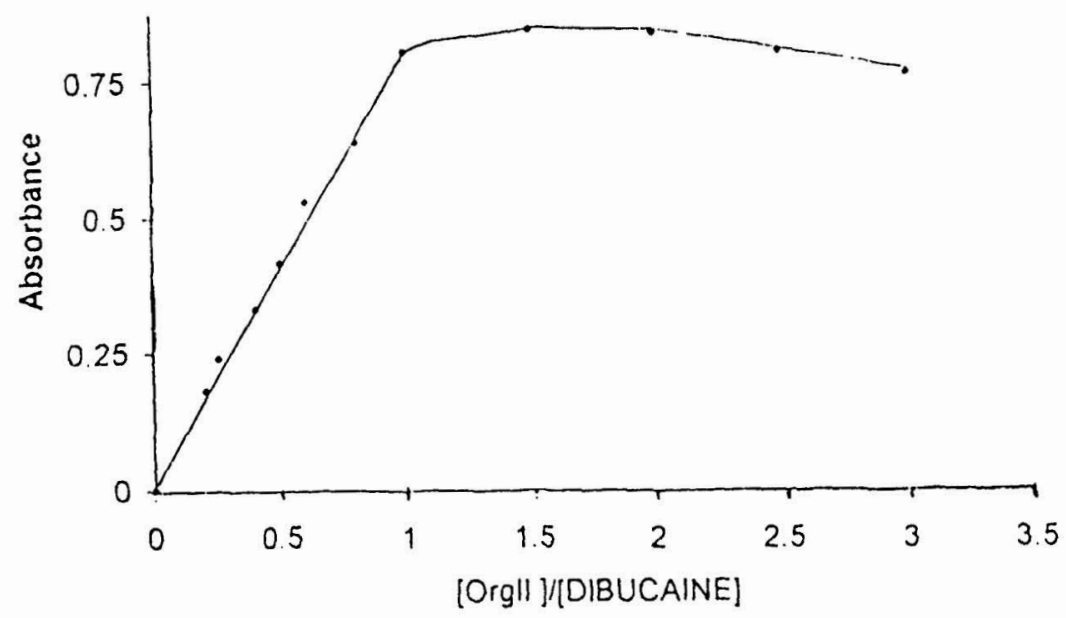

Figure 2

Molar ratio method for the determination of the stoichiometry of the ion-pair formed between Dibucaine and OrgIl at 486nm. 


\section{References:}

1- Miescher K.,(1932), Helv.Chim.Acta,15:163.

2- 'The Merck index", (1989), $11^{\text {th }}$ ed., centennial edition, New Jersuey, USA, 478.

3- Sewester C. S., (1994), Drug Facts and Comparisons, Facts and Comparisons, 2518.

4- Wilson C.O., Gisvold O, (1962), Textbook of Organic, Medical and

Pharmaceutical Chemistry, J.B.Liooincott, Philadelphia, PA, $4^{\text {th }}$ edn. , 528.

5- Alkalay D.,Carlsen S., Wagner W.E.,(1986), J. Analytical Letters, 14 (B20):1745.

6- Memorandum from CPSC's Directorate for Health Sciences, (1990), (toxicity).

7- Igrashi K., Kasuya F., Fukui M., Nanjyou N., ( 1987), Chem- Pharm- Bull., 35(7): 3033

8- Gupta R.N., ( 1994) , J. chromatogr.- B, Biomed-Appl., 661 (2) : 362

9- San M., Fernandez, M.M., Callejion M., Sanchez J.C., Perez A., (1996), Analyst,121: 681 .

10- Mohamed F.A., Mohamed A.M.I ., Mohamed H.A., (1996), Talanta, 43:1931

11- Yoe J.H., Jones A.L. (1994), Ind. Eng. Chem. Anal Edu. , 16:14 .

12- Sakai T., ( 1982), Analyst, $107: 640$

13-Igrashi K., Kasuya F., Mori E., Fukui M. (1987), J-Chromatogr, -Biomed-Appl. 59: 407 . 